\title{
Estallido renal en paciente con hidronefrosis crónica asintomática. A propósito de un caso y revisión de la literatura
}

\author{
Gómez de Vicente JM, Elices Apellániz M*, García Benedito P, Martín Martínez JC, \\ Torronteras Santiago JM.
}

Servicio de Urología, *Anatomía Patológica y **Radiología del Hospital del Escorial. Madrid

Actas Urol Esp. 2007;31(8):928-930

\section{RESUMEN}

ESTALLIDO RENAL EN PACIENTE CON HIDRONEFROSIS CRÓNICA ASINTOMÁTICA. A PROPÓSITO DE UN CASO Y REVISIÓN DE LA LITERATURA

Se estima que la presencia de anomalías renales en pacientes que sufren un traumatismo renal oscila entre el 4,4 y el 19\%. Presentamos un caso de un paciente cuya primera manifestación de una hidronefrosis crónica fue un estallido renal secundario a un traumatismo abdominal.

Palabras clave: Traumatismo renal. Hidronefrosis crónica.

\section{ABSTRACT}

SHATTERED KIDNEY IN A PATIENT WITH ASIMPTOMATIC CHRONIC HYDRONEPHROSIS. CASE REPORT AND LITERATURE REVIEW

The incidence of renal anomalies in patients who suffer a renal trauma is around 4.4 and 19\%. We introduce a case of a patient whose first sign of a chronic hydronefrosis was a renal burst secondary to an abdominal trauma.

Keywords: Renal trauma. Chronic hydronephrosis.

$\mathrm{S}^{\mathrm{e}}$ estima que la presencia de anomalías renaes en pacientes que sufren un traumatismo renal oscila entre el 4,4 y el $19 \%{ }^{1}$. Estos pacientes suelen presentar lesiones severas con traumatismos abdominales leves. Para su correcto manejo, es preciso un diagnóstico rápido apoyado en las imágenes obtenidas mediante tomografía axial computerizada. Presentamos el caso de un paciente que sufrió un estallido renal por un traumatismo abdominal menor.

\section{CASO CLINICO}

Varón de 64 años que ingresa de forma urgente por dolor y distensión abdominal tras caída accidental desde una escalera y traumatismo en flanco izquierdo. En todo momento el paciente permanece estable y consciente, pero refiere cada vez mayor dolor abdominal. Como único antecedente personal tiene una hipercolesterolemia que trata con una medicación que no recuerda. En la exploración, el abdomen está distendido y defiende a la palpación. Se solicita una analítica urgente de sangre y orina, pruebas de coagulación y una tomografía axial computarizada de abdomen y pelvis. En el análisis de orina presenta una leve microhematuria. La cifra de hemoglobina es de $13,1 \mathrm{~g} / \mathrm{dl}$, la coagulación es normal, el valor de creatinina de $1,2 \mathrm{mg} / \mathrm{dl}$, los iones normales y la amilasa $223 \mathrm{U} / \mathrm{L}$. El resto de la analítica es normal. En el TAC se identifica un riñón derecho normal y un riñón izquierdo de unos $35 \mathrm{~cm}$ de tamaño con un parénquima atrófico distorsionado en algunas zonas por sangrado activo. En la cavidad peritoneal se puede observar gran cantidad de líquido procedente del retroperitoneo izquierdo, cruzando por delante de la aorta (Fig. 1). Se decide realización urgente de laparotomía exploradora, identificando durante la misma una apertura en el peritoneo parietal en región paraaórtica izquierda de donde fluye un líquido hemo-urinoso. 


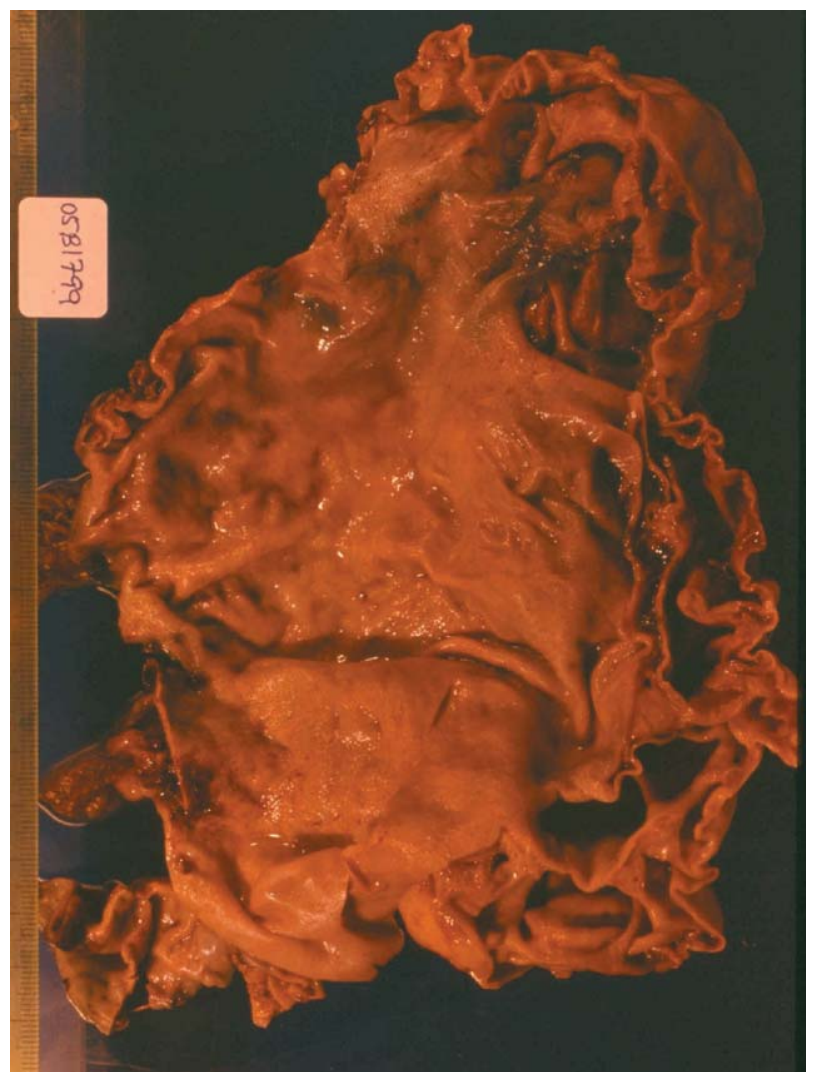

FIGURA 1

En retroperitoneo se aprecia un gran riñón hidronefrótico y atrófico con uréteropielocaliectasia hasta uréter pélvico, procediendo a su extirpación (Fig. 2). Durante el postoperatorio, el paciente presenta un pico febril de $38^{\circ} \mathrm{C}$ que remite tras iniciar fisioterapia respiratoria. Posteriormente el paciente queda asintomático siendo dado de alta con una función renal normal.

\section{DISCUSIÓN}

Varias series internacionales estiman que la incidencia de lesiones renales en pacientes traumatológicos oscila entre el 1,4 y el 3,25\% $\%^{2,3}$. La existencia de anomalías renales entre los adultos que sufren un traumatismo renal romo es de 4,4$19 \%{ }^{1}$. Similares cifras $(4,6-11,6 \%)$ se encuentran en la literatura nacional ${ }^{4,5}$.

En la infancia, la cifra es aun mayor $(12,6$ $35 \%)^{6-11}$.

Los traumatismos sobre riñones patológicos se caracterizan por acarrear lesiones severas con impactos a baja velocidad. Debido a ello, se asocian con menos frecuencia a lesiones en otros

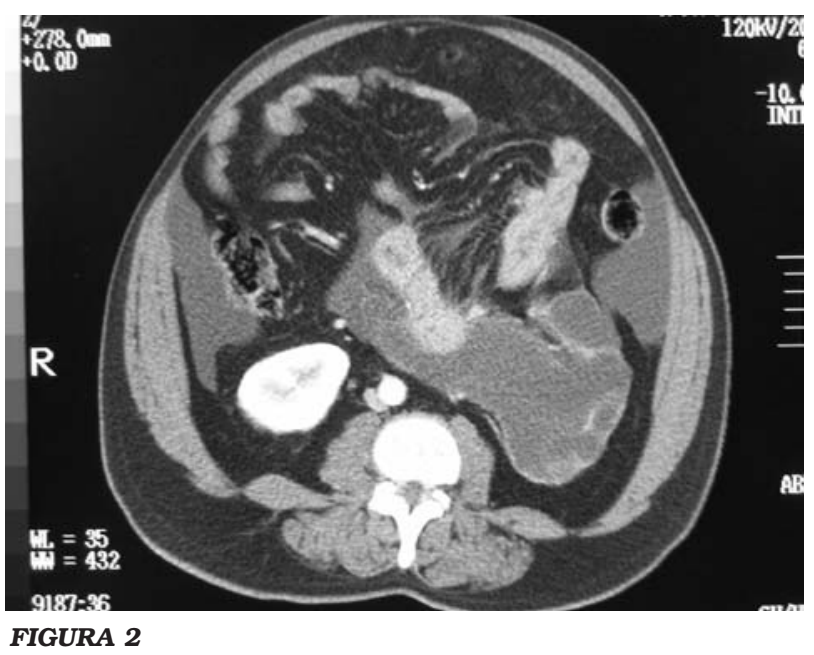

órganos intrabdominales. La causa de esta predisposición se ha atribuido a una menor resistencia tisular de los riñones hidronefróticos o con patología quística. En la infancia, esta predisposición es aún mayor debido a que tienen riñones proporcionalmente mayores y menos protegidos. Las anomalías más comúnmente encontradas por orden de frecuencia son: hidronefrosis, quistes, tumores y malposiciones renales. La mayor parte de las veces, los pacientes desconocen dichas anomalías. En más de la mitad de las ocasiones, la cirugía en estos pacientes está indicada por la patología existente en el riñón ${ }^{1}$ y no a la gravedad del traumatismo. En nuestro paciente el motivo era mixto, ya que al presentar una atrofia renal, el riñón debía extirparse y su estallido hacia la cavidad intraperitoneal provocaba una peritonitis química.

No todos los pacientes con lesiones renales precisan una evaluación radiológica. El TAC es la prueba princeps en estos casos. La indicación para realizar un TAC en los pacientes con sospecha de traumatismo renal, debe basarse en la historia clínica, la exploración física, el mecanismo lesivo, los hallazgos de laboratorio y el estado clínico. La finalidad de dicha evaluación es determinar qué lesiones precisan observación y cuales intervención inmediata o diferida. En pacientes adultos con traumatismos renales romos, el $12,5 \%$ de los que presentan hematuria macroscópica o microhematuria con presión arterial sistólica $<90 \mathrm{mmHg}$ tienen una lesión renal mayor (grados 2 a 5), por lo que la exploración radiológica está justificada ${ }^{12}$. Sin embargo, en este caso, 
la indicación para realizar el TAC fue la existencia de un abdomen agudo. El protocolo más comúnmente utilizado es el siguiente: TAC abdominal y pélvico, con una fase arterial o portal desde el diafragma hasta las tuberosidades isquiáticas, e imágenes en fase tardía, 10 minutos después, para valorar fuga de contraste de la vía urinaria.

Es llamativo en este caso, que debido al gran tamaño del riñón y la localización del traumatismo, su rotura impidiese al líquido expandirse por el retroperitoneo, produciendo una rotura del peritoneo parietal. La razón, probablemente se debió a la dirección del traumatismo y a la elevada tensión que se produjo en dicha zona. No obstante podría tratarse de una de las zonas de mayor debilidad del peritoneo parietal.

\section{CONCLUSIONES}

Debido a su menor resistencia frente a los golpes, la hidronefrosis crónica asintomática puede ponerse al descubierto ante un traumatismo abdominal leve, sufriendo incluso un estallido renal.

\section{REFERENCIAS}

1. Schmidlin FR, Iselin $\mathrm{CE}$, Naimi A, Rohner $\mathrm{S}$, Borst $\mathrm{F}$, Farshad M, Niederer P, Graber P. The higher injury risk of abnormal kidneys in blunt renal trauma. Scand $J$ Urol Nephrol. 1998;32:388-392.

2. Baverstock R, Simons R, McLoughlin M. Severe blunt renal trauma: a 7-year retrospective review from a provincial trauma center. Can J Urol 2001; 8: 1372-1376.

3. Cass AS, Luxenberg M, Gleich P et al. Clinical indications for radiographic evaluation of blunt renal trauma. J Urol. 1986;136:370-371.
4. Carcamo Valor PI, Hidalgo Togores L, Cozar Olmo JM, Garcia-Matres MJ, Navarro Sebastian J, Martinez-Pineiro JA. Our experience with the diagnosis and treatment of 429 renal traumatisms. Arch Esp Urol. 1991;44(7):801817.

5. Prieto Chaparro L, Silmi Moyano A, Delgado Martin JA, Paez Borda A, Blazquez Izquierdo J, Salinas Casado J et al. Renal injury on a pathological kidney. Incidence, management, and results of treatment. Arch Esp Urol. 1992;45 (5):407-413.

6. Ahmed S, Morris LL. Renal parenchymal injuries secondary to blunt abdominal trauma in childhood: a 10-year review. Br J Urol.1982;54:470-477.

7. Chopra P, St-Vil D, Yazbeck S. Blunt renal trauma-blessing in disguise?. J Pediatr Surg 2002; 37:779-782.

8. Esho JO, Ireland GW, Cass AS. Renal trauma and preexisting lesions of kidney. Urology 1973;1:134-135.

9. Onen A, Kaya M, Cigdem MK, JOtcu S, Ozturk H, Dokucu AI. Blunt renal trauma in children with previously undiagnosed pre-existing renal lesions and guidelines for effective initial management of kidney injury. BJU Int. 2002; 89:936-941.

10. Soler Soler JL, Nogueras Ocana M, Hidalgo Dominguez R, Martinez Torres JL, de la Fuente Serrano A, Zuluaga Gomez A. Renal trauma in children: our experience and review of the literature. Arch Esp Urol. 1994;47(1):51-57.

11. Carcamo Valor PI, Hidalgo Togores L, Cozar Olmo JM, Navarro Sebastian J, Garcia Matres MJ, Martinez-Pineiro JA. Kidney injuries in childhood: our experience in 64 cases. Arch Esp Urol 1990;43(6):651-655.

12. Mee SL, McAninch JW, Robinson AL, Auerbach PS, Carroll PR. Radiographic assessment of renal trauma: a 10-year prospective study of patient selection. J Urol 1989;141: 1095-1098.

Correspondencia autor: Dr. M. Gómez Vicente

Servicio de Urología. Hospital del Escorial.

Ctra. Guadarrama-San Lorenzo del Escorial km. 6,255 - 28200

San Lorenzo del Escorial (Madrid). Tel.: 918973000

e-mail autor: gomezvicente@telefonica.net

Información artículo: Nota clínica

Trabajo recibido: septiembre 2006

Trabajo aceptado: octubre 2006 